Article

\title{
Synthesis and Structure-Activity Relationship of Palmatine Derivatives as a Novel Class of Antibacterial Agents against Helicobacter pylori
}

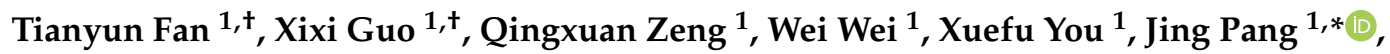 \\ Yanxiang Wang $1,2, * \mathbb{B}$ and Danqing Song ${ }^{1}$ \\ 1 Beijing Key Laboratory of Antimicrobial Agents, Institute of Medicinal Biotechnology, Chinese Academy of \\ Medical Sciences and Peking Union Medical College, Beijing 100050, China; fty1668@163.com (T.F.); \\ sissi.kwok@outlook.com (X.G.); zqx50810793@163.com (Q.Z.); weiwei082695@163.com (W.W.); \\ 13311123098@163.com (X.Y.); songdanqingsdq@hotmail.com (D.S.) \\ 2 State Key Laboratory of Bioactive Substance and Function of Natural Medicines, Institute of Materia Medica, \\ Chinese Academy of Medical Sciences and Peking Union Medical College, Beijing 100050, China \\ * Correspondence: pangjing.pangjing@163.com (J.P.); wangyanxiang@imb.pumc.edu.cn (Y.W.); \\ Tel.:+86-10-67058991 (J.P.); +86-10-63033012 (Y.W.) \\ + These authors contributed equally to this work.
}

Received: 24 February 2020; Accepted: 12 March 2020; Published: 16 March 2020

\begin{abstract}
Taking palmatine (PMT) as the lead, 20 new PMT derivatives were synthesized and examined for their antibacterial activities against six tested metronidazole (MTZ)-resistant Helicobacter pylori (H. pylori) strains. The structure-activity relationship (SAR) indicated that the introduction of a suitable secondary amine substituent at the 9-position might be beneficial for potency. Among them, compound 1c exhibited the most potent activities against MTZ-resistant strains, with minimum inhibitory concentration (MIC) values of $4-16 \mu \mathrm{g} / \mathrm{mL}$, better than that of the lead. It also exhibited a good safety profile with a half-lethal dose $\left(\mathrm{LD}_{50}\right)$ of over $1000 \mathrm{mg} / \mathrm{kg}$. Meanwhile, $1 \mathrm{c}$ might exert its antimicrobial activity through targeting $H$. pylori urease. These results suggested that PMT derivatives might be a new family of anti-H. pylori components.
\end{abstract}

Keywords: Helicobacter pylori; palmatine; synthesis; structure-activity relationship; urease

\section{Introduction}

Helicobacter pylori (H. pylori), spiral shaped gram-negative bacteria, has infected more than $50 \%$ of humans globally. It is believed that gastrointestinal diseases, such as gastritis and peptic ulcer, were highly related to $\mathrm{H}$. pylori infections [1]. Furthermore, the damage to gastric structure and function might lead to the development of gastric cancer, which becomes a major cause of morbidity and mortality worldwide [2,3]. H. pylori has been classified as a class I carcinogen by the World Health Organization (WHO) [4]. Currently, triple therapy regimens comprising amoxicillin and metronidazole (MTZ) or clarithromycin, as well as proton pump inhibitor, are recommended as first-line treatment for $H$. pylori infections [5,6]. However, the prevalence of antibiotic resistance, including MTZ and clarithromycin [3], decreased the efficacy and has become a great challenge to the clinical treatment. Thus, the discovery and development of novel agents against $H$. pylori to eradicate the pathogen is still of great importance.

Our group has been committed to exploring antibacterial agents with unique structure skeletons and novel mechanisms, and extensive efforts have been made on structural modifications and antibacterial activity explorations of protoberberine alkaloid [7-10]. Palmatine (PMT, Figure 1), a representative protoberberine alkaloid extracted from the traditional Chinese medicine Coptis chinensis, 
possesses a special quaternary ammonium in its structure and has diverse pharmacological and biological activities, including anti-inflammatory, anti-cancer, antiviral, and neuro-protection [11-13]. Meanwhile, PMT and its derivatives showed a potential as antibacterial candidates with their antibacterial efficacy against both gram-positive and gram-negative bacteria (including Staphylococcus aureus, Escherichia coli, and so on), which has been disclosed by different groups [14-16].

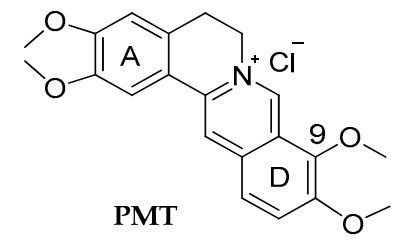

MIC: $100-200 \mathrm{ug} / \mathrm{mL}$

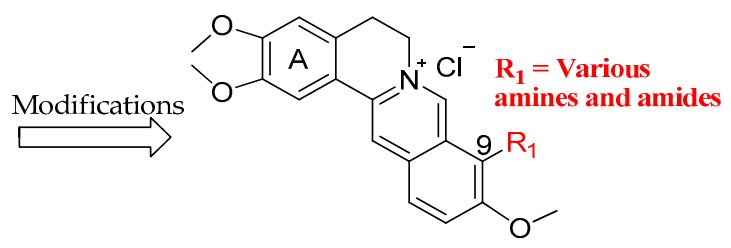

Target compounds

Figure 1. Chemical structure of palmatine (PMT), and structure modification strategy. MIC, minimum inhibitory concentration.

H. pylori creates a local neutral environment for survival by continuously releasing ammonia into succus gastricus, mediated by its own urease. Therefore, urease plays an essential role for $H$. pylori colonization in the human stomach, and is considered to be a critical target in the exploitation of anti-H. pylori agents [17-20]. Until now, no drug has been approved by Food and Drug Administration (FDA) targeting H. pylori urease [20,21]. As a novel $H$. pylori urease inhibitor, PMT exhibits bactericidal activity against $H$. pylori both in vitro and in vivo [22,23], as well as its potential therapeutic effects on gastritis and peptic ulcer caused by $H$. pylori infection, and other urea-related diseases have also been reported [24,25]. However, PMT only exhibited moderate potency with minimum inhibitory concentration (MIC) values of 100 to $200 \mu \mathrm{g} / \mathrm{mL}$, which need further improvement. Besides, the anti-H. pylori activity and structure-activity relationship (SAR) of its derivatives have not been investigated. Therefore, it was essential to conduct structural modification and anti-H. pylori activity screening on its kind, so as to acquire potent anti-H. pylori candidates.

As ionizable nitrogen is beneficial for the accumulation of small-molecule antibacterial in gram-negative bacteria [26], SAR study was mainly focused on the substituent at the 9-posision in the present study. Twenty new 9-N substituted PMT derivatives were prepared and evaluated for their anti-H. pylori activity, as depicted in Figure 1, taking PMT as the lead. Meanwhile, SAR analysis, safety evaluation and preliminary mechanism exploration of the representative compound are also described.

\section{Results and Discussion}

\subsection{Chemistry}

The synthetic route used for the preparations of all amine and amide derivatives of PMT is presented in Scheme 1. PMT was first heated with amines, which were used as the nucleophilic reagents and the solvents, to produce the corresponding amine derivatives $\mathbf{1 a}-\mathbf{j}$ and $\mathbf{2}$ in $31-57 \%$ yields $[27,28]$. Subsequently, compound 3 with a free amine was obtained using 2 and $\mathrm{HCl} / \mathrm{CH}_{3} \mathrm{OH}$ ( $1: 1$ by vol) as the reactive reagents with the yield of $73 \%$. Afterward, taking 3 and corresponding acyl chlorides as the reactive materials, the target products $4 \mathbf{a}-\mathbf{i}$ were acquired in $33-52 \%$ yields [27]. All the target compounds were purified via flash column chromatography on silica gel using $\mathrm{CH}_{2} \mathrm{Cl}_{2}$ and $\mathrm{MeOH}$ as eluent or washed with $\mathrm{CH}_{2} \mathrm{Cl}_{2}$ and $80 \% \mathrm{EtOH}$. 


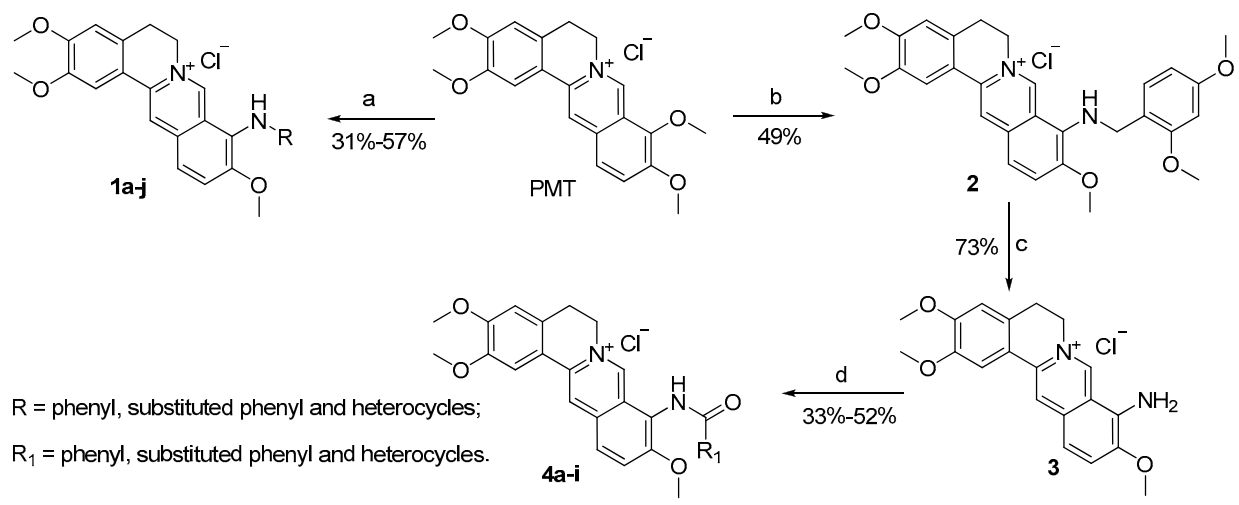

Scheme 1. Reagents and conditions: (a) $\mathrm{RNH}_{2}, 95-120{ }^{\circ} \mathrm{C}, 4-72 \mathrm{~h}$; (b) 2,4-dimethoxybenzylamine, $110{ }^{\circ} \mathrm{C}, 6 \mathrm{~h}$; (c) $1: 1 \mathrm{HCl} / \mathrm{CH}_{3} \mathrm{OH}$, room temperature (rt), $24 \mathrm{~h}$; (d) $\mathrm{R}_{1} \mathrm{COCl}$, pyridine, $\mathrm{CH}_{3} \mathrm{CN}, 71^{\circ} \mathrm{C}$, $3-24 \mathrm{~h}$.

\subsection{Pharmacological Evaluation}

The European Committee on Antimicrobial Susceptibility Testing (EUCAST) resistance breakpoint of MTZ to H. pylori was $>8 \mu \mathrm{g} / \mathrm{mL}[29,30]$. We carried out the SAR study for antibacterial activity against six different MTZ-resistant $H$. pylori strains including ATCC43504 and five clinical isolated strains from Chinese hospitals, taking PMT and MTZ as the positive controls. The chemical structures of 20 target compounds and their MIC values are depicted in Table 1.

Table 1. Antimicrobial activities of the target compounds against metronidazole (MTZ)-resistant H. pylori strains (minimum inhibitory concentration (MIC), $\mu \mathrm{g} / \mathrm{mL}$ ).

\begin{tabular}{|c|c|c|c|c|c|c|c|}
\hline Code & $\mathbf{R}$ & $\begin{array}{l}\text { ATCC } \\
43504^{a}\end{array}$ & $\begin{array}{c}\text { CСРMAP } \\
160007\end{array}$ & $\begin{array}{c}\text { CСРMAP } \\
160008\end{array}$ & $\begin{array}{c}\text { CСРMAP } \\
160010\end{array}$ & $\begin{array}{c}\text { CСРMAP } \\
160011\end{array}$ & $\begin{array}{c}\text { CСРMAP } \\
160017\end{array}$ \\
\hline PMT & - & 64 & 64 & 128 & 128 & 128 & 256 \\
\hline $1 \mathbf{a}$ & $\mathrm{C}_{6} \mathrm{H}_{5}$ & 32 & 8 & 64 & 16 & 64 & 64 \\
\hline $1 b$ & $m-\mathrm{CH}_{3} \mathrm{C}_{6} \mathrm{H}_{4}$ & 16 & 4 & 8 & 4 & 16 & 16 \\
\hline 1c & $p-\mathrm{CH}_{3} \mathrm{C}_{6} \mathrm{H}_{4}$ & 16 & 4 & 4 & 4 & 8 & 16 \\
\hline 1d & $p-\mathrm{CH}_{3} \mathrm{OC}_{6} \mathrm{H}_{4}$ & 16 & 4 & 32 & 8 & 16 & 32 \\
\hline $1 e$ & $m-\mathrm{CNC}_{6} \mathrm{H}_{4}$ & $>256$ & 128 & $>256$ & 256 & $>256$ & $>256$ \\
\hline 1f & $p-\mathrm{FC}_{6} \mathrm{H}_{4}$ & 128 & 64 & 128 & 8 & 128 & 128 \\
\hline $1 \mathrm{~g}$ & $p-\mathrm{BrC}_{6} \mathrm{H}_{4}$ & 64 & 8 & 16 & 4 & 64 & 64 \\
\hline $1 \mathrm{~h}$ & $2^{\prime}$-furyl & 32 & 8 & 64 & 16 & 16 & 16 \\
\hline $1 \mathbf{i}$ & $2^{\prime}$-pyridyl & 64 & 16 & 128 & 32 & 64 & 128 \\
\hline 2 & $2^{\prime}, 4^{\prime}-\left(\mathrm{CH}_{3} \mathrm{O}\right)_{2} \mathrm{C}_{6} \mathrm{H}_{3}$ & 16 & 4 & 32 & 4 & 16 & 16 \\
\hline 3 & - & $>128$ & $>128$ & $>128$ & $>128$ & $>128$ & $>128$ \\
\hline $4 a$ & $\mathrm{C}_{6} \mathrm{H}_{5}$ & $>256$ & 64 & $>256$ & $>256$ & $>256$ & $>256$ \\
\hline $4 b$ & $p-\left(\mathrm{CH}_{3}\right)_{3} \mathrm{CC}_{6} \mathrm{H}_{4}$ & $>256$ & 16 & $>256$ & 128 & $>256$ & $>256$ \\
\hline $4 c$ & $m-\mathrm{FC}_{6} \mathrm{H}_{4}$ & $>256$ & 128 & $>256$ & 256 & $>256$ & $>256$ \\
\hline $4 d$ & $2^{\prime}$-furyl & 256 & 128 & $>256$ & 256 & $>256$ & $>256$ \\
\hline $4 e$ & & 256 & 128 & $>256$ & 256 & $>256$ & $>256$ \\
\hline $4 \mathrm{f}$ & & $>256$ & 128 & $>256$ & 256 & $>256$ & $>256$ \\
\hline $4 g$ & $\pi^{i}$ & $>256$ & $>256$ & $>256$ & $>256$ & $>256$ & $>256$ \\
\hline $4 \mathrm{~h}$ & $\stackrel{0-N}{1}$ & $>256$ & $>256$ & $>256$ & $>256$ & $>256$ & $>256$ \\
\hline $4 i$ & $3^{\prime}$-pyridyl & $>256$ & $>256$ & $>256$ & $>256$ & $>256$ & $>256$ \\
\hline $\mathrm{MTZ}^{\mathrm{b}}$ & - & 128 & 32 & 32 & 16 & 64 & 128 \\
\hline
\end{tabular}

${ }^{a}$ H. pylori ATCC43504 strain served as MIC quality control (MTZ: $\left.64-256 \mu \mathrm{g} / \mathrm{mL}\right)$; ${ }^{\mathrm{b}}$ MTZ: $\leq 8 \mu \mathrm{g} / \mathrm{mL}$ for susceptible and $>8 \mu \mathrm{g} / \mathrm{mL}$ for resistant. 
As a start, a benzyl amine group was attached on position 9 and compound 1a was constructed. It exhibited comparable potencies against all the tested MTZ-resistant strains compared with those of positive controls. Subsequently, compounds $\mathbf{1 b}-\mathbf{d}$ and $\mathbf{2}$ were designed to explore the influence of electron-donating groups, including methyl and methoxy on the benzyl group. Among them, compounds $\mathbf{1 b}, \mathbf{1 c}$, and 2 with m-methyl, p-methyl, and $o, p$-methoxy benzyl amine substituent displayed better potencies than those of PMT and MTZ against all tested strains, with MIC values of 4-32 $\mu \mathrm{g} / \mathrm{mL}$. However, compound 1e with the electron-withdrawing group cyano-substituted lost its antibacterial activity. These results hinted that electron-donating groups on the benzyl group might be beneficial for antibacterial potency. Then, the fluorine and bromine atom, as the bioisosteres of the hydrogen atom, were attached on the benzyl amine substituent and 1f-g were created. All of them showed comparable activities to that of PMT and MTZ. After that, heterocyclic amine derivatives $\mathbf{1 h}$ and $1 \mathbf{i}$ were synthesized and screened, and compound $\mathbf{1 h}$ acquired improved potencies than those of positive controls. Finally, the efficacy of compound 3 with 9-amine substituted was eliminated totally, which suggested that appropriate substituted secondary amine on position 9 might be helpful for maintaining potency against MTZ-resistant H. pylori strains.

As a comparison, substituted amide analogues $4 \mathbf{a}-\mathbf{i}$ possessing less ionizable nitrogens on position 9 were designed and screened for their anti-H. pylori activities. As shown in Table 1, all of them lost the anti-H. pylori potencies partially or completely, suggesting that appropriate ionizable nitrogen might be essential for the activity.

Although different candidates are in various phases of discovery and development pipeline [17-20], no drugs with novel skeleton against $H$. pylori have been approved recently. Compound 1c with unique skeleton exhibited most the promising potency against $H$. pylori compared with PMT, and was selected as the representative compound for further investigation.

\subsection{Acute Toxicity Assay of Compound 1c}

Then, taking Kunming mice as the animal model, we performed an acute toxicity test on compound 1c through oral administration. All mice survived during the seven-day observation period, and had glossy hair, fleshy body, agile movement, and good appetite. The result indicated that the half-lethal dose $\left(\mathrm{LD}_{50}\right)$ value of compound $1 \mathrm{c}$ was over $1000 \mathrm{mg} / \mathrm{kg}$, suggesting a good safety feature.

\subsection{Molecular Docking Study of Key Compound 1c}

H. pylori expresses high levels of urease, which enables the survival and colonization of itself. To further explore the preliminary mechanism of compound 1c, molecular docking studies were conducted to calculate the interactions between compound 1c and PMT with $H$. pylori urease (Protein Data Bank (PDB): 1E9Y) [31], respectively. The LibDock score of compound 1c (104.13) with H. pylori urease was higher than that of PMT (92.14), which is consistent with the phenotype screening results.

The docking results of $H$. pylori urease with PMT and compound 1c are illustrated in Figure 2. Both of them could embed into the active hydrophobic pocket of $H$. pylori urease and fit well in the binding site (Figure 2A,C). Besides attractive charges and Pi-Alykl, several other typical interactions between 1c and H. pylori urease, including Pi-Pi T-shaped with residue HIS-221 and Pi-Anion with residue ASP-165, were predicted (Figure 2B), which together contributed to the stronger interactions and the higher docking score compared with those of PMT (Figure 2D). The results gave a possible explanation as to why 1c was more potent and suggested that 1c might act on $H$. pylori urease for mediating its anti-H. pylori activity. As appropriate substituents might enhance the interactions between PMT derivatives and urease, our docking data provided powerful information for further structural modifications of this kind. 


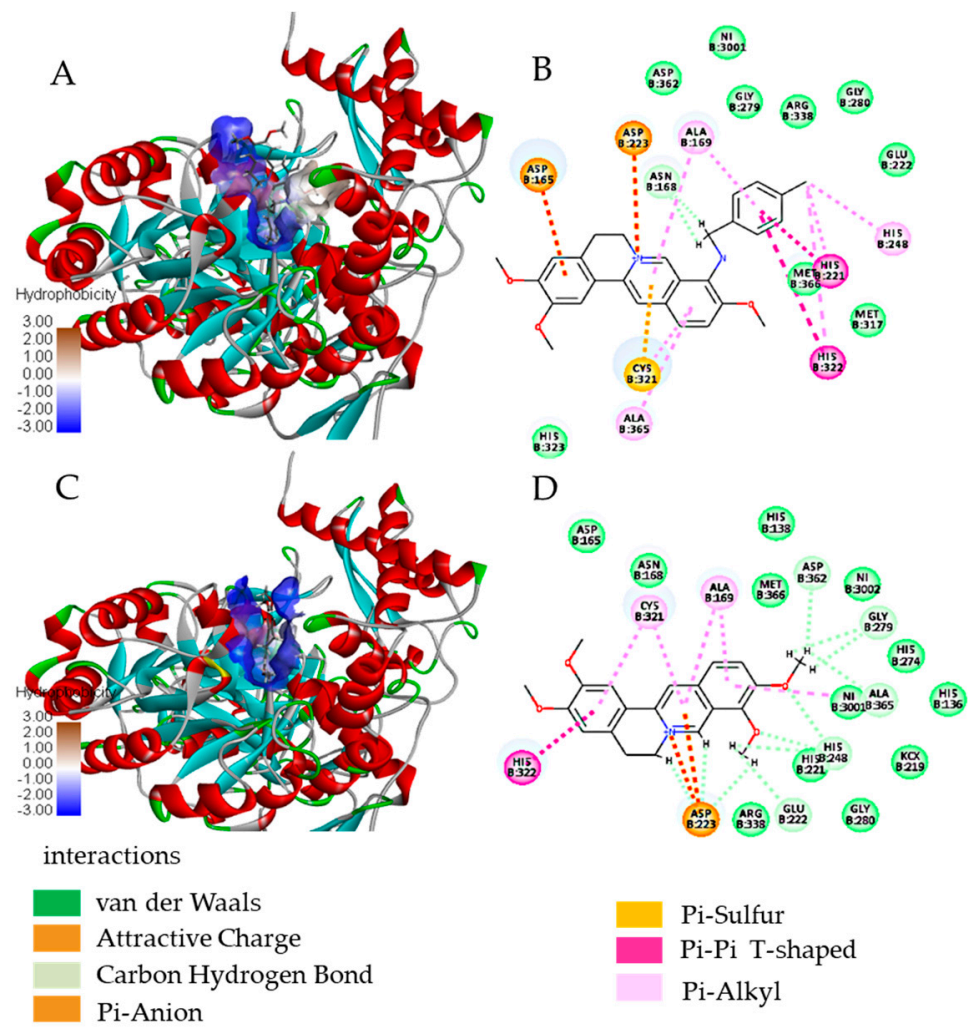

Figure 2. Solid surface maps of the active pocket of $H$. pylori urease with compound 1c (A) and PMT (C). Red, blue, and white colored regions correspond to negatively charged, positively charged, and neutral areas, respectively. Binding mode plans of 1c (B) and PMT (D) within the H. pylori urease active pocket. These figures were produced using the Discovery Studio 4.5 software. Van der Waals force, green; attractive charge force, orange; carbon hydrogen bond force, celadon; Pi-Anion force, orange; Pi-sulfur force, yellow; Pi-Pi T-shaped force, amaranth; Pi-alkyl force, mauve pink. The receptor structure is shown in surface form.

\subsection{The Inhibitory Effects on Urease of Compound 1c}

Considering that Jack bean urease shares a high sequence similarity and highly conserved catalytic mechanism with the H. pylori urease [32], the inhibitory effects of PMT and 1c at different concentrations on Jack bean urease were carried out to further validate the docking results. As shown in Figure 3, compound 1c could dose-dependently inhibit the activity of Jack bean urease, and the half maximal inhibitory concentration $\left(\mathrm{IC}_{50}\right)$ was $6.76 \pm 1.86 \mu \mathrm{g} / \mathrm{mL}$, much lower than that of PMT $(>32 \mu \mathrm{g} / \mathrm{mL})$, as anticipated. These data were in accordance with the phenotype screening and docking results. Therefore, $H$. pylori urease might be one of the targets of PMT derivatives. On the basis of these results, compound 1c might possess a different mechanism from the first-line anti-H. pylori drugs, which provided a possible explanation for the efficacy of compound 1c against MTZ-resistant $H$. pylori strains.
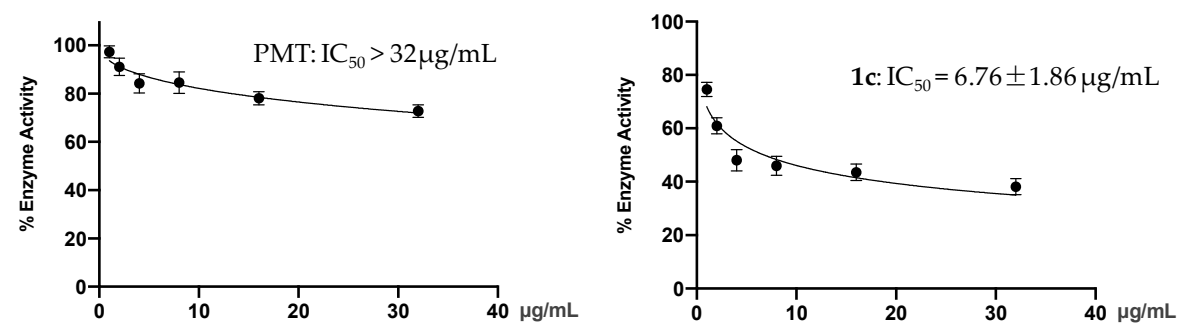

Figure 3. Effects of Palmatine (PMT) and 1c on the activity of Jack bean urease. 


\section{Experimental Section}

\subsection{Apparatus, Materials, and Analysis Reagents}

Melting point (mp) was obtained with MPA100 OptiMelt automated melting point system (Stanford Research Systems, Palo Alto, CA, USA) and uncorrected. The ${ }^{1} \mathrm{H}-\mathrm{NMR}$ and ${ }^{13} \mathrm{C}-\mathrm{NMR}$ spectra were performed on Bruker Avance $600 \mathrm{MHz}$ spectrometer (AV600-III, Bruker, Zürich, Swiss) with $\mathrm{Me}_{4} \mathrm{Si}$ as the internal standard, and all samples were dissolved in dimethyl sulfoxide (DMSO)- $d_{6}$ or $\mathrm{CD}_{3} \mathrm{OD}$ and $\mathrm{CDCl}_{3}$ before testing. High resolution mass spectra (HRMS)-electronic spray ion (ESI) data were recorded on an Autospec UItima-TOF mass spectrometer (Micromass UK Ltd., Manchester, UK). Flash chromatography was performed on CombiflashRf 200 (Teledyne, Lincoln, NE, USA), with a particle size of $0.038 \mathrm{~mm}$ (Figure S1-S20).

PMT was purchased from Xi'an Tianbao Biotechnology Co., Ltd. (Shanxi, China) with purity over 95\%. All of the other chemical reagents and anhydrous solvents were purchased from commercial sources (J\&K Scientific, Beijing, China) and used without further purification. H. pylori ATCC43504 is a standard strain purchased from American Type Culture Collection (ATCC), and other H. pylori strains obtained from CAMS Collection Center of Pathogen Microorganisms (CCPM) were isolated from gastric antrum in Beijing, China. MTZ and vancomycin were purchased from National Institutes for Food and Drug Control, Beijing, China. Trimethroprim, polymyxin B sulfate, amphotericin B, and cefsulodin sodium salt were purchased from Sangon Biotech Co., Ltd., Shanghai, China. Mueller-Hinton (MH) agar used for bacterial culture and antimicrobial susceptibility tests was purchased from Becton, Dickinson, and Company (Franklin Lakes, NJ, USA).

\subsection{General Synthesis Procedures for Compounds $\mathbf{1 a - i}$ and $\mathbf{2}$}

PMT (387 mg, $1.0 \mathrm{mmol})$ and corresponding amines $(15.0 \mathrm{mmol})$ were heated for $4-72 \mathrm{~h}$ at 95-120 ${ }^{\circ} \mathrm{C}$. (Table S1) Afterwards, the mixture was cooled and washed with ethyl acetate $(15 \mathrm{~mL})$ to remove the remaining amine. The residue was purified using flash column chromatography on silica gel with $\mathrm{CH}_{2} \mathrm{Cl}_{2} / \mathrm{MeOH}$ as gradient eluent to obtain the desired compounds $1 \mathbf{a}-\mathbf{i}$ and 2 (Figure S1-S20).

2,3,10-Trimethoxy-9-benzylaminoprotopalmatine chloride (1a): red solid; yield: 41\%; m.p.: $236-238{ }^{\circ} \mathrm{C}$; ${ }^{1} \mathrm{H}-\mathrm{NMR}\left(\mathrm{DMSO}-d_{6}\right) \delta 10.49(\mathrm{~s}, 1 \mathrm{H}), 8.79(\mathrm{~s}, 1 \mathrm{H}), 7.84(\mathrm{~d}, J=9.0 \mathrm{~Hz}, 1 \mathrm{H}), 7.67(\mathrm{~s}, 1 \mathrm{H}), 7.49(\mathrm{~d}, J=8.4 \mathrm{~Hz}$, $1 \mathrm{H}), 7.43-7.37(\mathrm{~m}, 3 \mathrm{H}), 7.28(\mathrm{t}, J=7.8 \mathrm{~Hz}, 2 \mathrm{H}), 7.22-7.15(\mathrm{tt}, J=7.2,1.2 \mathrm{~Hz}, 1 \mathrm{H}), 7.07(\mathrm{~s}, 1 \mathrm{H}), 4.83(\mathrm{t}$, $J=6.6 \mathrm{~Hz}, 2 \mathrm{H}), 4.79(\mathrm{~d}, J=6.6 \mathrm{~Hz}, 2 \mathrm{H}), 3.93(\mathrm{~s}, 3 \mathrm{H}), 3.86(\mathrm{~s}, 3 \mathrm{H}), 3.85(\mathrm{~s}, 3 \mathrm{H}), 3.23(\mathrm{t}, J=6.6 \mathrm{~Hz}, 2 \mathrm{H})$; ${ }^{13}$ C-NMR $\delta$ 151.7, 149.1, 147.0, 146.8, 141.1, 136.8, 136.4, 133.6, 128.7 (3), 127.9 (2), 127.2, 125.4, 119.8, $119.5,117.7,116.7,111.8,109.1,57.2,56.6,56.3,55.4,50.2,26.7$; HRMS: calcd for $\mathrm{C}_{27} \mathrm{H}_{27} \mathrm{~N}_{2} \mathrm{O}_{3} \mathrm{Cl}[\mathrm{M}-\mathrm{Cl}]^{+}$: 427.2016, found: 427.2012 .

2,3,10-Trimethoxy-9-m-methylbenzylaminoprotopalmatine chloride (1b): red solid; yield: 43\%; m.p.: 223-225 ${ }^{\circ} \mathrm{C} ;{ }^{1} \mathrm{H}-\mathrm{NMR}\left(\mathrm{DMSO}-\mathrm{d}_{6}\right) \delta 10.33(\mathrm{~s}, 1 \mathrm{H}), 8.79(\mathrm{~s}, 1 \mathrm{H}), 7.86(\mathrm{~d}, J=8.4 \mathrm{~Hz}, 1 \mathrm{H}), 7.67(\mathrm{~s}$, $1 \mathrm{H}), 7.50(\mathrm{~d}, J=8.4 \mathrm{~Hz}, 1 \mathrm{H}), 7.25-7.14(\mathrm{~m}, 4 \mathrm{H}), 7.07(\mathrm{~s}, 1 \mathrm{H}), 7.01(\mathrm{~d}, J=6.6 \mathrm{~Hz}, 1 \mathrm{H}), 4.81(\mathrm{t}, J=6.6 \mathrm{~Hz}$, $2 \mathrm{H}), 4.75(\mathrm{~d}, J=6.6 \mathrm{~Hz}, 2 \mathrm{H}), 3.92(\mathrm{~s}, 3 \mathrm{H}), 3.86(\mathrm{~s}, 6 \mathrm{H}), 3.22(\mathrm{t}, J=6.6 \mathrm{~Hz}, 2 \mathrm{H}), 2.26(\mathrm{~s}, 3 \mathrm{H}) ;{ }^{13} \mathrm{C}-\mathrm{NMR} \delta$ 151.2, 148.7, 146.6, 146.3, 140.5, 137.2, 136.4, 135.9, 133.1, 128.2, 128.1, 128.1, 127.4, 124.8, 124.5, 119.3, 119.0, 117.1, 116.3, 111.3, 108.5, 56.8, 56.1, 55.8, 55.0, 49.9, 26.3, 21.1; HRMS: calcd for $\mathrm{C}_{28} \mathrm{H}_{29} \mathrm{~N}_{2} \mathrm{O}_{3} \mathrm{Cl}$ $[\mathrm{M}-\mathrm{Cl}]^{+}:$441.2173, found: 441.2170 .

2,3,10-Trimethoxy-9-p-methylbenzylaminoprotopalmatine chloride (1c): red solid; yield: 48\%; m.p.: 234-236 ${ }^{\circ} \mathrm{C} ;{ }^{1} \mathrm{H}-\mathrm{NMR}\left(\mathrm{DMSO}-\mathrm{d}_{6}\right) \delta 10.42(\mathrm{~s}, 1 \mathrm{H}), 8.78(\mathrm{~s}, 1 \mathrm{H}), 7.83(\mathrm{~d}, J=8.4 \mathrm{~Hz}, 1 \mathrm{H}), 7.66(\mathrm{~s}$, $1 \mathrm{H}), 7.48(\mathrm{~d}, J=8.4 \mathrm{~Hz}, 1 \mathrm{H}), 7.32(\mathrm{t}, J=6.6 \mathrm{~Hz}, 1 \mathrm{H}), 7.28(\mathrm{~d}, J=7.8 \mathrm{~Hz}, 2 \mathrm{H}), 7.11-6.99(\mathrm{~m}, 3 \mathrm{H}), 4.82(\mathrm{t}$, $J=6.6 \mathrm{~Hz}, 2 \mathrm{H}), 4.78-4.69(\mathrm{~m}, 2 \mathrm{H}), 3.92(\mathrm{~s}, 3 \mathrm{H}), 3.86(\mathrm{~s}, 6 \mathrm{H}), 3.22(\mathrm{t}, J=6.6 \mathrm{~Hz}, 2 \mathrm{H}), 2.22(\mathrm{~s}, 3 \mathrm{H}) ;{ }^{13} \mathrm{C}-\mathrm{NMR}$ $\delta 151.1,148.6,146.5,146.3,137.5,136.3,135.8,135.8,133.1,128.8$ (2), 128.2, 127.5 (2), 124.8, 119.3, 119.0, 117.2, 116.2, 111.3, 108.5, 56.7, 56.1, 55.8, 54.9, 49.5, 26.3, 20.7; HRMS: calcd for $\mathrm{C}_{28} \mathrm{H}_{29} \mathrm{~N}_{2} \mathrm{O}_{3} \mathrm{Cl}[\mathrm{M}-\mathrm{Cl}]^{+}$: 441.2173, found: 441.212173 . 
2,3,10-Trimethoxy-9-p-methoxybenzylaminoprotopalmatine chloride (1d): red solid; yield: 57\%; m.p.: 232-234 ${ }^{\circ} \mathrm{C} ;{ }^{1} \mathrm{H}-\mathrm{NMR}\left(\mathrm{DMSO}-d_{6}\right) \delta 10.42(\mathrm{~s}, 1 \mathrm{H}), 8.78(\mathrm{~s}, 1 \mathrm{H}), 7.84(\mathrm{~d}, J=8.4 \mathrm{~Hz}, 1 \mathrm{H}), 7.66(\mathrm{~s}, 1 \mathrm{H})$, $7.49(\mathrm{~d}, J=8.4 \mathrm{~Hz}, 1 \mathrm{H}), 7.35-7.30(\mathrm{~m}, 2 \mathrm{H}), 7.29-7.20(\mathrm{~m}, 1 \mathrm{H}), 7.07(\mathrm{~s}, 1 \mathrm{H}), 6.86-6.80(\mathrm{~m}, 2 \mathrm{H}), 4.83(\mathrm{t}$, $J=6.6 \mathrm{~Hz}, 2 \mathrm{H}), 4.71(\mathrm{~d}, J=6.50 \mathrm{~Hz}, 2 \mathrm{H}), 3.92(\mathrm{~s}, 3 \mathrm{H}), 3.89(\mathrm{~s}, 3 \mathrm{H}), 3.86(\mathrm{~s}, 3 \mathrm{H}), 3.68(\mathrm{~s}, 3 \mathrm{H}), 3.22(\mathrm{t}$, $J=6.6 \mathrm{~Hz}, 2 \mathrm{H}) ;{ }^{13} \mathrm{C}-\mathrm{NMR} \delta 158.6,151.7,149.2,147.1,146.8,136.8,136.3,133.6,132.9,129.3$ (2), 128.7 , 125.2, 119.8, 119.5, 117.7, 116.7, 114.1 (2), 111.8, 109.1, 57.2, 56.6, 56.30, 55.4 (2), 49.8, 26.8; HRMS: calcd for $\mathrm{C}_{28} \mathrm{H}_{29} \mathrm{~N}_{2} \mathrm{O}_{4} \mathrm{Cl}[\mathrm{M}-\mathrm{Cl}]^{+}$: 457.2122, found: 457.2112 .

2,3,10-Trimethoxy-9-m-cyanobenzylaminoprotopalmatine chloride (1e): red solid; yield: 35\%; m.p.: 246-248 ${ }^{\circ} \mathrm{C} ;{ }^{1} \mathrm{H}-\mathrm{NMR}\left(\mathrm{DMSO}_{6}\right) \delta 10.41(\mathrm{~s}, 1 \mathrm{H}), 8.80(\mathrm{~s}, 1 \mathrm{H}), 7.85(\mathrm{~d}, J=8.4 \mathrm{~Hz}, 1 \mathrm{H}), 7.76(\mathrm{~d}$, $J=8.4 \mathrm{~Hz}, 2 \mathrm{H}), 7.68(\mathrm{~s}, 1 \mathrm{H}), 7.59(\mathrm{~d}, J=8.4 \mathrm{~Hz}, 2 \mathrm{H}), 7.52(\mathrm{~d}, J=9.0 \mathrm{~Hz}, 1 \mathrm{H}), 7.48(\mathrm{t}, J=7.2 \mathrm{~Hz}, 1 \mathrm{H}), 7.09$ $(\mathrm{s}, 1 \mathrm{H}), 4.89-4.70(\mathrm{~m}, 4 \mathrm{H}), 3.93(\mathrm{~s}, 3 \mathrm{H}), 3.87(\mathrm{~s}, 3 \mathrm{H}), 3.79(\mathrm{~s}, 3 \mathrm{H}), 3.24(\mathrm{t}, J=6.6 \mathrm{~Hz}, 2 \mathrm{H}) ;{ }^{13} \mathrm{C}-\mathrm{NMR} \delta$ 151.7, 149.2, 147.3, 146.9, 146.6, 136.6, 136.0, 133.8, 132.6 (2), 128.7, 128.6 (2), 125.7, 119.9, 119.5, 119.4, $117.9,117.2,111.8,109.9,109.1,57.2,56.6,56.3,55.6,49.9,26.7 ;$ HRMS: calcd for $\mathrm{C}_{28} \mathrm{H}_{26} \mathrm{~N}_{3} \mathrm{O}_{3} \mathrm{Cl}[\mathrm{M}-\mathrm{Cl}]^{+}$: 452.1969, found: 452.1973 .

2,3,10-trimethoxy-9-p-fluorobenzylaminoprotopalmatine chloride (1f): red solid; yield: 54\%; m.p.: $226-228^{\circ} \mathrm{C}$; ${ }^{1} \mathrm{H}-\mathrm{NMR}\left(\mathrm{DMSO}-d_{6}\right) \delta 10.44(\mathrm{~s}, 1 \mathrm{H}), 8.79(\mathrm{~s}, 1 \mathrm{H}), 7.85(\mathrm{~d}, J=9.0 \mathrm{~Hz}, 1 \mathrm{H}), 7.67(\mathrm{~s}, 1 \mathrm{H}), 7.50(\mathrm{~d}, J=9.0 \mathrm{~Hz}$, $1 \mathrm{H}), 7.47-7.40(\mathrm{~m}, 2 \mathrm{H}), 7.36(\mathrm{t}, J=6.6 \mathrm{~Hz}, 1 \mathrm{H}), 7.14-7.03(\mathrm{~m}, 3 \mathrm{H}), 4.82(\mathrm{t}, J=6.6 \mathrm{~Hz}, 2 \mathrm{H}), 4.75(\mathrm{~d}$, $J=6.0 \mathrm{~Hz}, 2 \mathrm{H}), 3.92(\mathrm{~s}, 3 \mathrm{H}), 3.86(\mathrm{~s}, 6 \mathrm{H}), 3.23(\mathrm{t}, J=6.6 \mathrm{~Hz}, 2 \mathrm{H}) ;{ }^{13} \mathrm{C}-\mathrm{NMR} \delta 161.1,151.2,148.7,146.6$, 146.3, 136.8, 136.8, 136.0 (2), 133.2, 129.4 (2), 128.2, 124.9, 119.3, 119.0, 117.4, 116.5, 114.9 (2), 111.3, 108.5, 56.7, 56.1, 55.8, 55.0, 49.0, 26.3; HRMS: calcd for $\mathrm{C}_{27} \mathrm{H}_{26} \mathrm{~N}_{2} \mathrm{O}_{3} \mathrm{FCl}$ [M-Cl] $]^{+}$:445.1922, found: 445.1922 .

2,3,10-Trimethoxy-9-p-bromobenzylaminoprotopalmatine chloride (1g): red solid; yield: 44\%; m.p.: 215-217 ${ }^{\circ} \mathrm{C} ;{ }^{1} \mathrm{H}-\mathrm{NMR}\left(\mathrm{DMSO}-\mathrm{d}_{6}\right) \delta 10.41-10.20(\mathrm{~s}, 1 \mathrm{H}), 8.79(\mathrm{~s}, 1 \mathrm{H}), 7.86(\mathrm{~d}, J=8.4 \mathrm{~Hz}, 1 \mathrm{H}), 7.67(\mathrm{~s}$, $1 \mathrm{H}), 7.51(\mathrm{~d}, J=8.4 \mathrm{~Hz}, 1 \mathrm{H}), 7.49-7.43(\mathrm{~m}, 2 \mathrm{H}), 7.35(\mathrm{~d}, J=8.4 \mathrm{~Hz}, 2 \mathrm{H}), 7.29(\mathrm{~d}, J=6.6 \mathrm{~Hz}, 1 \mathrm{H}), 7.08$ $(\mathrm{s}, 1 \mathrm{H}), 4.81(\mathrm{t}, J=6.6 \mathrm{~Hz}, 2 \mathrm{H}), 4.74(\mathrm{~d}, J=7.2 \mathrm{~Hz}, 2 \mathrm{H}), 3.92(\mathrm{~s}, 3 \mathrm{H}), 3.86(\mathrm{~s}, 3 \mathrm{H}), 3.85(\mathrm{~s}, 3 \mathrm{H}), 3.23(\mathrm{t}$, $J=6.6 \mathrm{~Hz}, 2 \mathrm{H}) ;{ }^{13} \mathrm{C}-\mathrm{NMR} \delta 151.2,148.7,146.6,146.2,140.1,136.0,135.8,133.2,131.1$ (2), 129.7 (2), 128.2 , $125.0,119.8,119.4,119.0,117.4,116.6,111.3,108.5,56.7,56.1,55.8,55.1,49.2,26.3$; HRMS: calcd for $\mathrm{C}_{27} \mathrm{H}_{26} \mathrm{~N}_{2} \mathrm{O}_{3} \mathrm{BrCl}[\mathrm{M}-\mathrm{Cl}]^{+}$: 505.1121, found: 505.1121.

2,3,10-Trimethoxy-9-(1-(furan-2-yl)methylamino)protopalmatine chloride (1h): red solid; yield: 19\%; m.p.: 231-233 ${ }^{\circ} \mathrm{C} ;{ }^{1} \mathrm{H}-\mathrm{NMR}\left(\mathrm{DMSO}-d_{6}\right) \delta 10.21(\mathrm{~s}, 1 \mathrm{H}), 8.84(\mathrm{~s}, 1 \mathrm{H}), 7.93(\mathrm{~d}, J=8.4 \mathrm{~Hz}, 1 \mathrm{H}), 7.68(\mathrm{~s}, 1 \mathrm{H}), 7.60$ $(\mathrm{d}, J=8.4 \mathrm{~Hz}, 1 \mathrm{H}), 7.52(\mathrm{dd}, J=1.8,0.6 \mathrm{~Hz}, 1 \mathrm{H}), 7.08(\mathrm{~s}, 1 \mathrm{H}), 6.87(\mathrm{t}, J=6.6 \mathrm{~Hz}, 1 \mathrm{H}), 6.33(\mathrm{dd}, J=3.0$, $1.8 \mathrm{~Hz}, 1 \mathrm{H}), 6.29-6.12(\mathrm{~m}, 1 \mathrm{H}), 4.83(\mathrm{t}, J=6.6 \mathrm{~Hz}, 2 \mathrm{H}), 4.75(\mathrm{~d}, J=6.6 \mathrm{~Hz}, 2 \mathrm{H}), 3.94(\mathrm{~s}, 3 \mathrm{H}), 3.93(\mathrm{~s}, 3 \mathrm{H})$, $3.87(\mathrm{~s}, 3 \mathrm{H}), 3.23(\mathrm{t}, J=6.4 \mathrm{~Hz}, 2 \mathrm{H}) ;{ }^{13} \mathrm{C}-\mathrm{NMR} \delta 154.0,151.7,149.2,147.9,146.6,142.6,136.6,136.0,133.7$, 128.7, 125.5, 120.0, 119.5, 118.3, 118.0, 111.8, 110.8, 109.1, 107.6, 57.3, 56.6, 56.3, 55.6, 43.9, 26.7; HRMS: calcd for $\mathrm{C}_{25} \mathrm{H}_{25} \mathrm{~N}_{2} \mathrm{O}_{4} \mathrm{Cl}[\mathrm{M}-\mathrm{Cl}]^{+}$: 417.1809 , found: 417.1811 .

2,3,10-Trimethoxy-9-(1-(pyridyl-2-yl)methylamino)protopalmatine chloride (1i): red solid; yield: 35\%; m.p.: 199-201 ${ }^{\circ} \mathrm{C} ;{ }^{1} \mathrm{H}-\mathrm{NMR}\left(\mathrm{DMSO}-\mathrm{d}_{6}\right) \delta 10.29(\mathrm{~s}, 1 \mathrm{H}), 8.81(\mathrm{~s}, 1 \mathrm{H}), 8.56(\mathrm{ddd}, J=5.4,1.2,0.6 \mathrm{~Hz}, 1 \mathrm{H}), 7.88(\mathrm{~d}$, $J=9.0 \mathrm{~Hz}, 1 \mathrm{H}), 7.78(\mathrm{td}, J=7.8,1.8 \mathrm{~Hz}, 1 \mathrm{H}), 7.69(\mathrm{~s}, 1 \mathrm{H}), 7.53(\mathrm{~d}, J=8.4 \mathrm{~Hz}, 1 \mathrm{H}), 7.46(\mathrm{~d}, J=7.8 \mathrm{~Hz}, 1 \mathrm{H})$, 7.37-7.24 (m, 2H), $7.09(\mathrm{~s}, 1 \mathrm{H}), 4.94(\mathrm{~d}, J=4.8 \mathrm{~Hz}, 2 \mathrm{H}), 4.85(\mathrm{t}, J=6.0 \mathrm{~Hz}, 2 \mathrm{H}), 3.93(\mathrm{~s}, 3 \mathrm{H}), 3.87(\mathrm{~s}, 3 \mathrm{H})$, $3.84(\mathrm{~s}, 3 \mathrm{H}), 3.24(\mathrm{t}, J=6.6 \mathrm{~Hz}, 2 \mathrm{H}) ;{ }^{13} \mathrm{C}-\mathrm{NMR} \delta 158.9,151.1,148.6,146.6,146.3,136.8,136.6,135.7,133.0$, $128.1,124.2,122.2,121.6,121.5,119.3,118.9,116.6,116.2,111.3,108.5,56.9,56.1,55.7,55.0,51.6,26.2$; HRMS: calcd for $\mathrm{C}_{26} \mathrm{H}_{26} \mathrm{~N}_{3} \mathrm{O}_{3} \mathrm{Cl}[\mathrm{M}-\mathrm{Cl}]^{+}$: 428.1969 , found: 428.1968 .

2,3,10-Trimethoxy-9-o,p-dimethoxybenzylamino protopalmatine chloride (2): red solid; yield: 52\%; m.p.: 176-178 ${ }^{\circ} \mathrm{C} ;{ }^{1} \mathrm{H}-\mathrm{NMR}\left(\mathrm{DMSO}-\mathrm{d}_{6}\right) \delta 10.02(\mathrm{~s}, 1 \mathrm{H}), 8.82(\mathrm{~s}, 1 \mathrm{H}), 7.88(\mathrm{~d}, J=9.0 \mathrm{~Hz}, 1 \mathrm{H}), 7.68(\mathrm{~s}, 1 \mathrm{H}), 7.55$ $(\mathrm{d}, J=9.0 \mathrm{~Hz}, 1 \mathrm{H}), 7.14(\mathrm{~d}, J=8.4 \mathrm{~Hz}, 1 \mathrm{H}), 7.09(\mathrm{~s}, 1 \mathrm{H}), 6.52(\mathrm{~d}, J=1.8 \mathrm{~Hz}, 1 \mathrm{H}), 6.45(\mathrm{~s}, 1 \mathrm{H}), 6.40(\mathrm{dd}$, $J=8.4,1.8 \mathrm{~Hz}, 1 \mathrm{H}), 4.83(\mathrm{t}, J=6.0 \mathrm{~Hz}, 2 \mathrm{H}), 4.66(\mathrm{~d}, J=3.0 \mathrm{~Hz}, 2 \mathrm{H}), 3.93(\mathrm{~s}, 3 \mathrm{H}), 3.87(\mathrm{~s}, 3 \mathrm{H}), 3.86(\mathrm{~s}, 3 \mathrm{H})$, $3.77(\mathrm{~s}, 3 \mathrm{H}), 3.71(\mathrm{~s}, 3 \mathrm{H}), 3.23(\mathrm{t}, J=6.0 \mathrm{~Hz}, 2 \mathrm{H}) ;{ }^{13} \mathrm{C}-\mathrm{NMR} \delta 160.3,158.3,151.6,149.1,147.7,146.8,137.2$, 136.3, 133.5, 130.0, 128.6, 124.8, 120.2, 119.9, 119.5, 117.9, 117.4, 111.8, 109.0, 104.6, 98.7, 57.3, 56.6, 56.3, 55.8, 55.6 (2), 46.8, 26.7; HRMS: calcd for $\mathrm{C}_{29} \mathrm{H}_{31} \mathrm{~N}_{2} \mathrm{O}_{5} \mathrm{Cl}[\mathrm{M}-\mathrm{Cl}]^{+}$: 487.2227, found: 487.2227. 


\subsection{Synthesis of 3}

2,3,10-Trimethoxy-9-aminoprotopalmatine chloride (3): The mixture of compound 2 (522 $\mathrm{mg}, 1.00 \mathrm{mmol}$ ) and methanol/ $\mathrm{HCl}$ (1:1 by vol., $20 \mathrm{~mL}$ ) was reacted at room temperature for $24 \mathrm{~h}$ (Table S1). Then, the solution was stopped and concentrated, and the residue was further purified through flash column chromatography on silica gel with $\mathrm{CH}_{3} \mathrm{OH} / \mathrm{CH}_{2} \mathrm{Cl}_{2}$ as the eluents to get the desired compound 3 as a red solid, yield: 73\%; m.p.: $266-268{ }^{\circ} \mathrm{C} ;{ }^{1} \mathrm{H}-\mathrm{NMR}\left(\mathrm{DMSO}-d_{6}\right) \delta 10.35(\mathrm{~s}, 1 \mathrm{H}), 8.72(\mathrm{~s}, 1 \mathrm{H}), 7.84(\mathrm{~d}$, $J=8.4 \mathrm{~Hz}, 1 \mathrm{H}), 7.66(\mathrm{~s}, 1 \mathrm{H}), 7.34(\mathrm{~d}, J=9.0 \mathrm{~Hz}, 1 \mathrm{H}), 7.07(\mathrm{~s}, 1 \mathrm{H}), 6.90(\mathrm{~s}, 2 \mathrm{H}), 4.74(\mathrm{t}, J=6.0 \mathrm{~Hz}, 2 \mathrm{H})$, $3.98(\mathrm{~s}, 3 \mathrm{H}), 3.93(\mathrm{~s}, 3 \mathrm{H}), 3.86(\mathrm{~s}, 3 \mathrm{H}), 3.22(\mathrm{t}, J=6.0 \mathrm{~Hz}, 2 \mathrm{H}) ;{ }^{13} \mathrm{C}-\mathrm{NMR} \delta$ 151.4, 149.1, 147.0, 143.7, 138.0, 135.6, 132.3, 128.4, 123.1, 119.7, 119.5, 113.8, 113.2, 111.8, 108.9, 56.9, 56.6, 56.3, 55.3, 26.8; HRMS: calcd for $\mathrm{C}_{20} \mathrm{H}_{21} \mathrm{~N}_{2} \mathrm{O}_{3} \mathrm{Cl}[\mathrm{M}-\mathrm{Cl}]^{+}$: 337.1547, found: 337.1547 .

\subsection{General Procedure for the Synthesis of Compounds $4 \mathbf{4}-\mathbf{i}$}

To a stirred solution of compound $3(100 \mathrm{mg}, 0.27 \mathrm{mmol})$ in anhydrous $\mathrm{CH}_{3} \mathrm{CN}(6 \mathrm{~mL})$, pyridine $(1.22 \mathrm{mmol})$ and corresponding acyl chloride $(0.81 \mathrm{mmol})$ were added. The reaction mixture was heated at $71{ }^{\circ} \mathrm{C}$ for 3-24 h (Table S1). The mixture was cooled and filtered, and the resulting residue was washed with $\mathrm{CH}_{2} \mathrm{Cl}_{2}$ and $80 \% \mathrm{EtOH}$ to acquired desired compounds $4 \mathbf{a}-\mathbf{i}$ (Figure $\mathrm{S} 1-\mathrm{S} 20$ ).

2,3,10-Trimethoxy-9-benzoylaminoprotopalmatine chloride (4a): yellow solid; yield: 37\%; m.p.: $215-217^{\circ} \mathrm{C}$; ${ }^{1} \mathrm{H}-\mathrm{NMR}$ (DMSO- $\left.d_{6}\right) \delta 10.47(\mathrm{~s}, 1 \mathrm{H}), 9.76(\mathrm{~s}, 1 \mathrm{H}), 9.14(\mathrm{~s}, 1 \mathrm{H}), 8.28(\mathrm{q}, J=9.0 \mathrm{~Hz}, 2 \mathrm{H}), 8.17-8.12(\mathrm{~m}, 2 \mathrm{H})$, $7.76(\mathrm{~s}, 1 \mathrm{H}), 7.70-7.64(\mathrm{~m}, 1 \mathrm{H}), 7.60(\mathrm{t}, J=7.2 \mathrm{~Hz}, 2 \mathrm{H}), 7.10(\mathrm{~s}, 1 \mathrm{H}), 4.98(\mathrm{t}, J=6.6 \mathrm{~Hz}, 2 \mathrm{H}), 4.03(\mathrm{~s}, 3 \mathrm{H})$, $3.95(\mathrm{~s}, 3 \mathrm{H}), 3.87(\mathrm{~s}, 3 \mathrm{H}), 3.22(\mathrm{t}, J=6.6 \mathrm{~Hz}, 2 \mathrm{H}) ;{ }^{13} \mathrm{C}-\mathrm{NMR} \delta 175.7,164.3,161.0,158.2,155.5,147.3,143.0$, 142.8, 141.5, 138.2, 137.9, 137.7 (2), 137.2 (2), 134.8, 133.9, 131.3, 130.0, 128.4, 120.8, 118.3, 66.4, 65.7, 65.4, 64.8, 35.4; HRMS: calcd for $\mathrm{C}_{27} \mathrm{H}_{25} \mathrm{~N}_{2} \mathrm{O}_{4} \mathrm{Cl}$ [M-Cl] ${ }^{+}$: 441.1809, found: 441.1812 .

2,3,10-Trimethoxy-9-p-tert-butylbenzoylaminoprotopalmatine chloride (4b): yellow solid; yield: $45 \%$; m.p.: 210-212 ${ }^{\circ} \mathrm{C} ;{ }^{1} \mathrm{H}-\mathrm{NMR}$ (DMSO- $\left.d_{6}\right) \delta 10.36(\mathrm{~s}, 1 \mathrm{H}), 9.73(\mathrm{~s}, 1 \mathrm{H}), 9.13(\mathrm{~s}, 1 \mathrm{H}), 8.39-8.21(\mathrm{~m}, 2 \mathrm{H}), 8.15-7.99$ $(\mathrm{m}, 2 \mathrm{H}), 7.75(\mathrm{~s}, 1 \mathrm{H}), 7.67-7.53(\mathrm{~m}, 2 \mathrm{H}), 7.10(\mathrm{~s}, 1 \mathrm{H}), 4.97(\mathrm{t}, J=6.6 \mathrm{~Hz}, 2 \mathrm{H}), 4.03(\mathrm{~s}, 3 \mathrm{H}), 3.96(\mathrm{~s}, 3 \mathrm{H})$, $3.87(\mathrm{~s}, 3 \mathrm{H}), 3.21(\mathrm{t}, J=6.6 \mathrm{~Hz}, 2 \mathrm{H}), 1.36(\mathrm{~s}, 9 \mathrm{H}) ;{ }^{13} \mathrm{C}-\mathrm{NMR} \delta 166.0,155.0,154.8,151.5,148.7,146.0,137.8$, 133.3, 130.8, 128.7, 128.1 (2), 127.6, 125.3, 125.2 (2), 124.5, 122.0, 120.5, 118.9, 111.3, 108.8, 56.9, 56.2, 55.9, 55.3, 34.8, 31.0 (3), 25.9; HRMS: calcd for $\mathrm{C}_{31} \mathrm{H}_{33} \mathrm{~N}_{2} \mathrm{O}_{4} \mathrm{Cl}$ [M-Cl] ${ }^{+}$: 497.2435, found: 497.2434.

2,3,10-Trimethoxy-9-p-fluorobenzoylaminoprotopalmatine chloride (4c): yellow solid; yield: 49\%; m.p.: 239-241 ${ }^{\circ} \mathrm{C} ;{ }^{1} \mathrm{H}-\mathrm{NMR}$ (DMSO- $\left.d_{6}\right): \delta 10.63(\mathrm{~s}, 1 \mathrm{H}), 9.80(\mathrm{~s}, 1 \mathrm{H}), 9.15(\mathrm{~s}, 1 \mathrm{H}), 8.42-8.19(\mathrm{~m}, 2 \mathrm{H}), 8.07-7.86$ $(\mathrm{m}, 2 \mathrm{H}), 7.76(\mathrm{~s}, 1 \mathrm{H}), 7.69-7.63(\mathrm{~m}, 1 \mathrm{H}), 7.54(\mathrm{td}, J=9.0,2.4 \mathrm{~Hz}, 1 \mathrm{H}), 7.10(\mathrm{~s}, 1 \mathrm{H}), 4.98(\mathrm{t}, J=6.6 \mathrm{~Hz}$, 2H), $4.03(\mathrm{~s}, 3 \mathrm{H}), 3.96(\mathrm{~s}, 3 \mathrm{H}), 3.87(\mathrm{~s}, 3 \mathrm{H}), 3.22(\mathrm{t}, J=6.6 \mathrm{~Hz}, 2 \mathrm{H}) ;{ }^{13} \mathrm{C}-\mathrm{NMR} \delta 164.9,162.8,161.2,154.8$, 151.5, 148.7, 145.9, 137.8, 135.9, 133.4, 130.6, 130.6, 128.7, 127.9, 125.3, 124.4, 124.3, 121.35, 120.48, 118.9, 115.1, 115.0, 111.3, 108.9, 57.0, 56.2, 55.9, 55.3, 25.9; HRMS: calcd for $\mathrm{C}_{27} \mathrm{H}_{24} \mathrm{~N}_{2} \mathrm{O}_{4} \mathrm{FCl}[\mathrm{M}-\mathrm{Cl}]^{+}: 459.1715$, found: 459.1711 .

2,3,10-Trimethoxy-9-(2'-furoylamino)protopalmatine chloride (4d): yellow solid; yield: 37\%; m.p.: 244-246 ${ }^{\circ} \mathrm{C} ;{ }^{1} \mathrm{H}-\mathrm{NMR}\left(\mathrm{CD}_{3} \mathrm{OD}, \mathrm{CDCl}_{3}\right) \delta 9.44(\mathrm{~s}, 1 \mathrm{H}), 8.75(\mathrm{~s}, 1 \mathrm{H}), 8.24(\mathrm{~d}, J=9.0 \mathrm{~Hz}, 1 \mathrm{H}), 8.06$ $(\mathrm{d}, J=9.0 \mathrm{~Hz}, 1 \mathrm{H}), 7.73(\mathrm{dd}, J=2.4,1.2 \mathrm{~Hz}, 1 \mathrm{H}), 7.56(\mathrm{~s}, 1 \mathrm{H}), 7.37(\mathrm{dd}, J=3.6,0.6 \mathrm{~Hz}, 1 \mathrm{H}), 6.93(\mathrm{~s}$, $1 \mathrm{H}), 6.66(\mathrm{dd}, J=3.6,1.8 \mathrm{~Hz}, 1 \mathrm{H}), 4.88(\mathrm{t}, J=6.6 \mathrm{~Hz}, 2 \mathrm{H}), 4.10(\mathrm{~s}, 3 \mathrm{H}), 4.02(\mathrm{~s}, 3 \mathrm{H}), 3.95(\mathrm{~s}, 3 \mathrm{H}), 3.25$ $(\mathrm{t}, J=6.6 \mathrm{~Hz}, 2 \mathrm{H}) ;{ }^{13} \mathrm{C}-\mathrm{NMR} \delta 159.4,155.6,153.2,150.3,147.4,146.6,146.4,139.1,134.8,129.0$ (2), 125.4, 124.9, 121.5, 121.0, 119.5, 117.3, 113.2, 111.6, 109.1, 57.4, 57.1, 56.9, 56.6, 27.5; HRMS: calcd for $\mathrm{C}_{25} \mathrm{H}_{23} \mathrm{~N}_{2} \mathrm{O}_{5} \mathrm{Cl}[\mathrm{M}-\mathrm{Cl}]^{+}: 431.1602$, found: 431.1604 .

2,3,10-Trimethoxy-9-(2',5'-dimethyl-3'-furoylamino)protopalmatine chloride (4e): yellow solid; yield: 40\%; m.p.: $236-238^{\circ} \mathrm{C} ;{ }^{1} \mathrm{H}-\mathrm{NMR}$ (DMSO- $\left.d_{6}\right) \delta 9.87(\mathrm{~s}, 1 \mathrm{H}), 9.67(\mathrm{~s}, 1 \mathrm{H}), 9.12(\mathrm{~s}, 1 \mathrm{H}), 8.30-8.18(\mathrm{~m}, 2 \mathrm{H}), 7.75$ $(\mathrm{s}, 1 \mathrm{H}), 7.10(\mathrm{~s}, 1 \mathrm{H}), 6.83(\mathrm{~s}, 1 \mathrm{H}), 4.99(\mathrm{t}, J=6.6 \mathrm{~Hz}, 2 \mathrm{H}), 4.03(\mathrm{~s}, 3 \mathrm{H}), 3.95(\mathrm{~s}, 3 \mathrm{H}), 3.87(\mathrm{~s}, 3 \mathrm{H}), 3.22(\mathrm{t}$, $J=6.6 \mathrm{~Hz}, 2 \mathrm{H}), 2.51(\mathrm{~s}, 3 \mathrm{H}), 2.32(\mathrm{~s}, 3 \mathrm{H}) ;{ }^{13} \mathrm{C} \mathrm{NMR} \delta 162.9,155.7,154.7,151.5,149.2,148.7,146.1,137.7$, 
133.3, 128.7, 127.5, 125.2, 124.5, 121.6, 120.4, 118.9, 116.0, 111.3, 108.8, 105.7, 56.9, 56.2, 55.9, 55.4, 26.0, 13.4, 13.1; HRMS: calcd for $\mathrm{C}_{27} \mathrm{H}_{27} \mathrm{~N}_{2} \mathrm{O}_{5} \mathrm{Cl}[\mathrm{M}-\mathrm{Cl}]^{+}:$: 459.1915, found: 459.1914 .

2,3,10-Trimethoxy-9-(1',5'-dimethyl-1'H-pyrazole-3'-ylcarbonylamino)protopalmatine chloride (4f): yellow solid; yield: 42\%; m.p.: $192-194{ }^{\circ} \mathrm{C} ;{ }^{1} \mathrm{H}-\mathrm{NMR}$ (DMSO-d $\left.d_{6}\right) \delta 9.92(\mathrm{~s}, 1 \mathrm{H}), 9.65(\mathrm{~s}, 1 \mathrm{H}), 9.12(\mathrm{~s}, 1 \mathrm{H})$, 8.30-8.12 (m, 2H), $7.74(\mathrm{~s}, 1 \mathrm{H}), 7.10(\mathrm{~s}, 1 \mathrm{H}), 6.62(\mathrm{~s}, 1 \mathrm{H}), 4.97(\mathrm{t}, J=6.6 \mathrm{~Hz}, 2 \mathrm{H}), 4.00(\mathrm{~s}, 3 \mathrm{H}), 3.95(\mathrm{~s}, 3 \mathrm{H})$, $3.89(\mathrm{~s}, 3 \mathrm{H}), 3.87(\mathrm{~s}, 3 \mathrm{H}), 3.21(\mathrm{t}, J=6.6 \mathrm{~Hz}, 2 \mathrm{H}), 2.36(\mathrm{~s}, 3 \mathrm{H}),{ }^{13} \mathrm{C}-\mathrm{NMR} \delta 161.1,154.6,151.5,148.7,146.2$, 143.9, 140.7, 137.5, 133.2, 128.6, 127.4, 125.2, 124.3, 121.6, 120.4, 118.9, 111.3, 108.8, 106.3, 56.9, 56.2, 55.9, 55.4, 36.6, 26.0, 10.8; HRMS: calcd for $\mathrm{C}_{26} \mathrm{H}_{27} \mathrm{~N}_{4} \mathrm{O}_{4} \mathrm{Cl}[\mathrm{M}-\mathrm{Cl}]^{+}$: 459.2027, found: 459.2029.

2,3,10-Trimethoxy-9-(3',5'-dimethylisoxazole-4'-ylcarbonylamino)protopalmatine chloride (4g): brown solid; yield: $47 \%$; m.p.: $262-264{ }^{\circ} \mathrm{C}$; ${ }^{1} \mathrm{H}-\mathrm{NMR}\left(\mathrm{CD}_{3} \mathrm{OD}, \mathrm{CDCl}_{3}\right) \delta 9.61(\mathrm{~s}, 1 \mathrm{H}), 8.85(\mathrm{~s}, 1 \mathrm{H}), 8.32(\mathrm{~d}, J=9.0 \mathrm{~Hz}$, $1 \mathrm{H}), 8.14(\mathrm{~d}, J=9.0 \mathrm{~Hz}, 1 \mathrm{H}), 7.64(\mathrm{~s}, 1 \mathrm{H}), 7.01(\mathrm{~s}, 1 \mathrm{H}), 4.97(\mathrm{t}, J=6.6 \mathrm{~Hz}, 2 \mathrm{H}), 4.16(\mathrm{~s}, 3 \mathrm{H}), 4.06(\mathrm{~s}, 3 \mathrm{H})$, $4.00(\mathrm{~s}, 3 \mathrm{H}), 3.32(\mathrm{~d}, J=6.6 \mathrm{~Hz}, 2 \mathrm{H}), 2.79(\mathrm{~s}, 3 \mathrm{H}), 2.56(\mathrm{~s}, 3 \mathrm{H}) ;{ }^{13} \mathrm{C}-\mathrm{NMR} \delta$ 173.0, 163.8, 159.9, 155.7, 153.4, $150.5,146.5,139.4,135.0,129.3$ (2), 125.5, 125.0, 121.6, 121.4, 119.7, 113.1, 111.8, 109.4, 57.5, 57.2, 56.9, 56.7, 27.5, 13.0, 11.3; HRMS: calcd for $\mathrm{C}_{26} \mathrm{H}_{26} \mathrm{~N}_{3} \mathrm{O}_{5} \mathrm{Cl}[\mathrm{M}-\mathrm{Cl}]^{+}: 460.1867$, found: 460.1870 .

2,3,10-Trimethoxy-9-(5'-methyl-3'-phenylisoxazole-4'-ylcarbonylamino)protopalmatine chloride (4h): yellow solid; yield: 35\%; m.p.: $221-223{ }^{\circ} \mathrm{C} ;{ }^{1} \mathrm{H}-\mathrm{NMR}$ (DMSO- $\left.d_{6}\right) \delta 10.38(\mathrm{~s}, 1 \mathrm{H}), 9.54(\mathrm{~s}, 1 \mathrm{H}), 9.12(\mathrm{~s}, 1 \mathrm{H}), 8.30$ $(\mathrm{s}, 2 \mathrm{H}), 7.85(\mathrm{~s}, 2 \mathrm{H}), 7.74(\mathrm{~s}, 1 \mathrm{H}), 7.53(\mathrm{~s}, 3 \mathrm{H}), 7.12(\mathrm{~s}, 1 \mathrm{H}), 4.95(\mathrm{~s}, 2 \mathrm{H}), 4.11(\mathrm{~s}, 3 \mathrm{H}), 3.95(\mathrm{~s}, 3 \mathrm{H}), 3.88(\mathrm{~s}$, $3 \mathrm{H}), 3.25(\mathrm{t}, J=6.6 \mathrm{~Hz}, 2 \mathrm{H}), 2.81(\mathrm{~s}, 3 \mathrm{H}),{ }^{13} \mathrm{C}-\mathrm{NMR} \delta$ 172.5, 162.3, 161.5, 155.4, 152.7 (2), 149.8 (2), 146.1, 138.8, 134.4, 130.7, 129.3 (3), 129.0, 128.8, 125.6, 124.4, 121.1, 119.5, 112.7, 111.8 (2), 109.4(2), 57.3, 56.7, 56.5, 56.2, 26.7, 12.6; HRMS: calcd for $\mathrm{C}_{31} \mathrm{H}_{28} \mathrm{~N}_{3} \mathrm{O}_{5} \mathrm{Cl}[\mathrm{M}-\mathrm{Cl}]^{+}$: 522.2024, found: 522.2028.

2,3,10-Trimethoxy-9-nicotinoylaminoprotopalmatine chloride (4i): yellow solid; yield: 36\%; m.p.: $248-250^{\circ} \mathrm{C}$; ${ }^{1} \mathrm{H}-\mathrm{NMR}\left(\mathrm{CD}_{3} \mathrm{OD}, \mathrm{CDCl}_{3}\right) \delta 9.98(\mathrm{~s}, 1 \mathrm{H}), 9.65(\mathrm{~d}, J=2.4 \mathrm{~Hz}, 1 \mathrm{H}), 9.34-9.28(\mathrm{~m}, 1 \mathrm{H}), 9.09-9.03(\mathrm{~m}$, $1 \mathrm{H}), 8.85(\mathrm{~s}, 1 \mathrm{H}), 8.35(\mathrm{~d}, J=9.0 \mathrm{~Hz}, 1 \mathrm{H}), 8.26(\mathrm{dd}, J=8.4,6.0 \mathrm{~Hz}, 1 \mathrm{H}), 8.14(\mathrm{~d}, J=9.0 \mathrm{~Hz}, 1 \mathrm{H}), 7.64$ $(\mathrm{s}, 1 \mathrm{H}), 6.99(\mathrm{~s}, 1 \mathrm{H}), 5.03(\mathrm{t}, J=6.6 \mathrm{~Hz}, 2 \mathrm{H}), 4.14(\mathrm{~s}, 3 \mathrm{H}), 4.07(\mathrm{~s}, 3 \mathrm{H}), 4.00(\mathrm{~s}, 3 \mathrm{H}), 3.31(\mathrm{t}, J=6.6 \mathrm{~Hz}$, 2H); ${ }^{13}$ C-NMR $\delta 163.6,156.1,153.3,150.4,146.4,145.6$ (2), 143.9, 139.5, 135.1, 133.8, 129.7, 129.3, 127.8, 125.6, 125.2, 121.6, 120.6, 119.6, 111.7, 109.3, 57.5, 56.9, 56.9, 56.6, 27.5; HRMS: calcd for $\mathrm{C}_{26} \mathrm{H}_{24} \mathrm{~N}_{3} \mathrm{O}_{4} \mathrm{Cl}$ $[\mathrm{M}-\mathrm{Cl}]^{+}: 442.1761$, found: 442.1767 .

\subsection{Biology Assay}

\subsubsection{Antimicrobial Assay}

Six H. pylori strains from CAMS Collection Center of Pathogen Microorganisms (CCPM), including H. pylori strain ATCC43504, a standard strain isolated from human gastric antrum in Australia, and five clinical isolated strains from Chinese hospitals, were employed in the antibacterial activities study. MICs of the target compounds against $H$. pylori were performed using the agar dilution method following Clinical and Laboratory Standards Institute (CLSI) guidelines (M45). Briefly, the bacterial suspension adjusted to 2.0 McFarland density (about $10^{8} \mathrm{CFU} / \mathrm{mL}$ ) was prepared from an $\mathrm{MH}$ agar plate $(9 \mathrm{~cm})$ containing $5 \%$ defibrinated sheep blood and selective antibiotics (e.g., vancomycin, trimethroprim, polymyxin B sulfate, amphotericin B, and cefsulodin sodium salt) [33]. Then, $2.5 \mu \mathrm{L}$ of the bacterial suspension in triplicate was directly inoculated onto the $\mathrm{MH}$ agar plates with $5 \%$ defibrinated sheep blood containing 2-fold serial dilutions of test compounds $(0.5-256 \mu \mathrm{g} / \mathrm{mL})$. The plates were incubated at $37^{\circ} \mathrm{C}$ for $72 \mathrm{~h}$ under microaerobic conditions $\left(10 \% \mathrm{CO}_{2}\right)$. H. pylori ATCC 43504 strain was used as a control strain. The MICs were defined as the lowest concentration of drug showing no growth. The MIC results were obtained from two independent experiments. The resistance breakpoint for MTZ was defined as $>8 \mu \mathrm{g} / \mathrm{mL}$. 


\subsubsection{Acute Toxicity}

The weights of sixteen experimental female and sixteen male Kunming mice were $20.0 \pm 1.0 \mathrm{~g}$. They were purchased from the Institute of Laboratory Animal Science (Beijing, China). According to the institutional guidelines of the Institute of Materia Medica, CAMS\&PUMC, all mice were fed with regular rodent chow and housed in an air-conditioned room. The mice were randomly allocated into different groups with four female and four male in each group. The compound $\mathbf{1} \mathbf{c}$ was given orally in a single-dosing experiment at $0,250,500$, or $1000 \mathrm{mg} / \mathrm{kg}$ (saline as control), respectively. The mice were closely monitored for seven days. Body weight as well as survival was monitored. Animal experiments were approved by the Ethics Committee of the Institute of Medicinal Biotechnology, Chinese Academy of Medical Sciences and Peking Union Medical College, Beijing, China, with the approval number of IBM20190510D201 (Approval date: 05/10/2019).

\subsubsection{Molecular Docking Assay}

Crystal structure of $H$. pylori urease was obtained from the Protein Data Bank (PDB code 1E9Y, resolution: $3 \AA$ ) [31]. The binding modes between $H$. pylori urease and 1c or PMT were generated using the LibDock software within Discovery Studio v4.5 (BIOVIA, San Diego, CA, USA). Before docking, protein structure and ligands were processed by Discovery Studio v4.5, such as ligand energy minimization, protein preparation, and so on [34]. The receptor ligand interaction with the highest docking score in the Discovery Studio v4.5 software was the final result of the docking experiment.

\subsubsection{Enzyme Inhibition Assay}

Urease (Type III from Canavalia ensiformis; Sigma-Aldrich, St. Louis, MO, USA) $0.05 \mathrm{mg} / \mathrm{mL}$ and different concentrations of $1 \mathrm{c}(1,2,4,8,16$, and $32 \mu \mathrm{g} / \mathrm{mL})$ or PMT $(1,2,4,8,16$, and $32 \mu \mathrm{g} / \mathrm{mL})$ were incubated at $37^{\circ} \mathrm{C}$ in assay buffer in the absence of urea for $20 \mathrm{~min}$. Then, the reactions were initiated by mixing the urea and incubating for $10 \mathrm{~min}$ at room temperature [22,35]. The urease activity was determined by Urease Activity Assay Kit (Sigma-Aldrich).

\section{Conclusions}

Taking PMT as the lead, 20 new derivatives were synthesized and examined for their antibacterial activities against different MTZ-resistant $H$. pylori strains. SAR analysis indicated that the introduction of a suitable secondary amine substituent at the 9-position might be beneficial for potency. Among them, compound 1c exhibited the most potent activities against MTZ-resistant strains with MIC values of $4-16 \mu \mathrm{g} / \mathrm{mL}$, better than those of PMT and MTZ. Compound 1c exhibited a good safety character, with an $\mathrm{LD}_{50}$ of over $1000 \mathrm{mg} / \mathrm{kg}$ by oral administration. Molecular docking and enzyme inhibition assay verified that $1 \mathrm{c}$ might act on $H$. pylori urease for mediating its activity. Therefore, we consider PMT derivatives to be a new family of anti-MTZ-resistant $H$. pylori components.

Supplementary Materials: The following are available online, Figures S1-S20: Spectra of the analyzed target compounds $\mathbf{1 a}-\mathbf{i}, \mathbf{2}, \mathbf{3}, \mathbf{4} \mathbf{a}-\mathbf{i}$, Table S1: The reaction times and temperatures of each target compounds.

Author Contributions: T.F., X.G., and W.W. performed part of synthetic experiments and wrote the paper; J.P., Q.Z., and X.Y. conceived and designed the biology experiments; Y.W. and D.S. designed the target compounds and chemistry experiments. All authors have read and agreed to the published version of the manuscript.

Funding: This work was supported by the CAMS initiative for innovative medicine (2019-I2M-1-005, 2017-I2M-1-012; 2016-I2M-1-011) and the National Natural Science Foundation of China (81603195).

Acknowledgments: The authors thank the center for analysis and testing of Institute of Materia Medica and Institute of Medicinal Biotechnology, Chinese Academy of Medical Sciences for their contributions to the determination of HR-MS, ${ }^{1} \mathrm{H}-\mathrm{NMR}$, and ${ }^{13} \mathrm{C}-\mathrm{NMR}$.

Conflicts of Interest: The authors declare no conflict of interest. 


\section{References}

1. Kishikawa, H.; Ojiro, K.; Nakamura, K.; Katayama, T.; Arahata, K.; Takarabe, S.; Miura, S.; Kanai, T.; Nishida, J. Previous Helicobacter pylori infection-induced atrophic gastritis: A distinct disease entity in an understudied population without a history of eradication. Helicobacter 2019, 3. [CrossRef] [PubMed]

2. Zhang, F.; Chen, C.; Hu, J.; Su, R.; Zhang, J.; Han, Z.; Chen, H.; Li, Y. Molecular mechanism of Helicobacter pylori-induced autophagy in gastric cancer. Oncol. Lett. 2019, 18, 6221-6227. [CrossRef] [PubMed]

3. Pichon, M.; Broutin, L.; Touroult-Jupin, P.; Cremniter, J.; Plouzeau, C.; Faure, J.P.; Olivier, R.; Burucoa, C. First detection in Helicobacter suis of a mutation conferring resistance to clarithromycin in Helicobacter pylori: Case report and review of the literature. Microb. Drug Resist. 2019. [CrossRef] [PubMed]

4. Kumar, S.; Metz, D.C.; Ellenberg, S.; Kaplan, D.E.; Goldberg, D.S. Risk factors and incidence of gastric cancer after detection of Helicobacter pylori infection: A large cohort study. Gastroenterology 2019. [CrossRef]

5. Kato, M.; Ota, H.; Okuda, M.; Kikuchi, S.; Satoh, K.; Shimoyama, T.; Suzuki, H.; Handa, O.; Furuta, T.; Mabe, K.; et al. Guidelines for the management of Helicobacter pylori infection in Japan. Helicobacter 2019, 24. [CrossRef]

6. Gisbert, J.P.; McNicholl, A.G. Optimization strategies aimed to increase the efficacy of H. pylori eradication therapies. Helicobacter 2017, 22. [CrossRef]

7. Liu, Y.X.; Xiao, C.L.; Wang, Y.X.; Li, Y.H.; Yang, Y.H.; Li, Y.B.; Bi, C.W.; Gao, L.M.; Jiang, J.D.; Song, D.Q. Synthesis, structure-activity relationship and in vitro anti-mycobacterial evaluation of 13-n-octylberberine derivatives. Eur. J. Med. Chem. 2012, 52, 151-158. [CrossRef]

8. Fan, T.Y.; Wang, Y.X.; Tang, S.; Hu, X.X.; Zeng, Q.X.; Pang, J.; Yang, Y.S.; You, X.F.; Song, D.Q. Synthesis and antibacterial evaluation of 13-substituted cycloberberine derivatives as a novel class of anti-MRSA agents. Eur. J. Med. Chem. 2018, 157, 877-886. [CrossRef]

9. Fan, T.Y.; Hu, X.X.; Tang, S.; Liu, X.J.; Wang, Y.X.; Deng, H.B.; You, X.F.; Jiang, J.D.; Li, Y.H.; Song, D.Q. Discovery and development of 8-substituted cycloberberine derivatives as novel antibacterial agents against MRSA. ACS Med. Chem. Lett. 2018, 9, 484-489. [CrossRef]

10. Yang, Y.S.; Wei, W.; Hu, X.X.; Tang, S.; Pang, J.; You, X.F.; Fan, T.Y.; Wang, Y.X.; Song, D.Q. Evolution and antibacterial evaluation of 8-hydroxy-cycloberberine derivatives as a novel family of antibacterial agents against MRSA. Molecules 2019, 24, 984. [CrossRef]

11. Tarabasz, D.; Kukula-Koch, W. Palmatine: A review of pharmacological properties and pharmacokinetics. Phytother. Res. 2019. [CrossRef] [PubMed]

12. Chang, Y.L.; Usami, S.; Hsieh, M.T.; Jiang, M.J. Effects of palmatine on isometric force and intracellular calcium levels of arterial smooth muscle. Life Sci. 1999, 64, 597-606. [CrossRef]

13. Vennerstrom, J.L.; Klayman, D.L. Protoberberine Alkaloids as Antimalarials. J. Med. Chem. 1988, 31, 1084-1087. [CrossRef] [PubMed]

14. Li, Z.C.; Kong, X.B.; Mai, W.P.; Sun, G.C.; Zhao, S.Z. Synthesis and antimicrobial activity of 9-o-substituted palmatine derivatives. Indian J. Pharm. Sci. 2015, 77, 196-201. [CrossRef] [PubMed]

15. Ma, T.W.; Ye, X.L.; Li, X.G.; Zhang, B.S.; Jiang, X.F.; Chen, Z. Synthesis and antimicrobial activity of 8-alkylpalmatine derivatives. Lett. Drug Des. Discov. 2011, 8, 464-468. [CrossRef]

16. Song, L.; Zhang, H.J.; Deng, A.J.; Li, J.; Li, X.; Li, Z.H.; Zhang, Z.H.; Wu, L.Q.; Wang, S.Q.; Qin, H.L. Syntheses and structure-activity relationships on antibacterial and anti-ulcerative colitis properties of quaternary 13-substituted palmatines and 8-oxo-13-substituted dihydropalmatines. Bioorg. Med. Chem. 2018, 26, 2586-2598. [CrossRef]

17. Menteşe, E.; Akyuz, G.; Emirik, M.; Baltaş, N. Synthesis, in vitro urease inhibition and molecular docking studies of some novel quinazolin-4 $(3 \mathrm{H})$-one derivatives containing triazole, thiadiazole and thiosemicarbazide functionalities. Bioorg. Chem. 2019, 83, 289-296. [CrossRef]

18. Alomari, M.; Taha, M.; Imran, S.; Jamil, W.; Selvaraj, M.; Uddin, N.; Rahim, F. Design, synthesis, in vitro evaluation, molecular docking and ADME properties studies of hybrid bis-coumarin with thiadiazole as a new inhibitor of Urease. Bioorg. Chem. 2019, 92. [CrossRef]

19. Liu, Q.; Shi, W.K.; Ren, S.Z.; Ni, W.W.; Li, W.Y.; Chen, H.M.; Liu, P.; Yuan, J.; He, X.S.; Liu, J.J.; et al. Arylamino containing hydroxamic acids as potent urease inhibitors for the treatment of Helicobacter pylori infection. Eur. J. Med. Chem. 2018, 156, 126-136. [CrossRef] 
20. Li, W.Y.; Ni, W.W.; Ye, Y.X.; Fang, H.L.; Pan, X.M.; He, J.L.; Zhou, T.L.; Yi, J.; Liu, S.S.; Zhou, M.; et al. $\mathrm{N}$-monoarylacetothioureas as potent urease inhibitors: Synthesis, SAR, and biological evaluation. J. Enzyme Inhib. Med. Chem. 2020, 35, 404-413. [CrossRef]

21. Bailie, N.C.; Osborne, C.A.; Leininger, J.R.; Fletcher, T.F.; Johnston, S.D.; Ogburn, P.N.; Griffith, D.P. Teratogenic effect of acetohydroxamic acid in clinically normal beagles. Am. J. Vet. Res. 1986, 47, 2604-2611. [PubMed]

22. Zhou, J.T.; Li, C.L.; Tan, L.H.; Xu, Y.F.; Liu, Y.H.; Mo, Z.Z.; Dou, Y.X.; Su, R.; Su, Z.R.; Huang, P.; et al. Inhibition of Helicobacter pylori and its associated urease by palmatine: Investigation on the potential mechanism. PLoS ONE 2017, 12. [CrossRef] [PubMed]

23. Rong, Q.; Xu, M.; Dong, Q.; Zhang, Y.L.; Li, Y.L.; Ye, G.; Zhao, L. In vitro and in vivo bactericidal activity of Tinospora sagittata (Oliv.) Gagnep. var. craveniana (S.Y.Hu) Lo and its main effective component, palmatine, against porcine Helicobacter pylori. BMC Complement Altern. Med. 2016, 16, 331. [CrossRef] [PubMed]

24. National Pharmacopoeia Committee. Pharmacopoeia of Peoples Republic of China, 2015 ed.; Chinese Medical Science and Technology Press: Beijing, China, 2015; ISBN 978-7-5067-7337-9.

25. Jung, J.; Choi, J.S.; Jeong, C.S. Inhibitory Activities of Palmatine from Coptis chinensis Against Helicobactor pylori and Gastric Damage. Toxicol. Res. 2014, 30, 45-48. [CrossRef] [PubMed]

26. Richter, M.F.; Drown, B.S.; Riley, A.P.; Garcia, A.; Shirai, T.; Svec, R.L.; Hergenrother, P.J. Predictive compound accumulation rules yield a broad-spectrum antibiotic. Nature 2017, 545, 299-304. [CrossRef]

27. Wang, Y.X.; Pang, W.Q.; Zeng, Q.X.; Deng, Z.S.; Fan, T.Y.; Jiang, J.D.; Deng, H.B.; Song, D.Q. Synthesis and biological evaluation of new berberine derivatives as cancer immunotherapy agents through targeting IDO1. Eur. J. Med. Chem. 2018, 143, 1858-1868. [CrossRef]

28. Naruto, S.; Mizuta, H.; Nishimura, H. A novel amination of isoquinolinium salts via nucleophilic substitution reaction. Tetrahedron Lett. 1976, 17, 1597-1600. [CrossRef]

29. European Committee on Antimicrobial Susceptibility Testing. Breakpoint Tables for Interpretation of MICs and Zone Diameters, version 5.0. 2015. Available online: http://www.eucast.org (accessed on 14 February 2019).

30. Wang, G.Z.; Pang, J.; Hu, X.X.; Nie, T.Y.; Lu, X.; Li, X.; Wang, X.K.; Lu, Y.; Yang, X.Y.; Jiang, J.D.; et al. Daphnetin: A Novel Anti-Helicobacter pylori Agent. Int. J. Mol. Sci. 2019, 20, 850. [CrossRef]

31. Ha, N.C.; Oh, S.T.; Sung, J.Y.; Cha, K.A.; Oh, B.H. Supramolecular assembly and acid resistance of Helicobacter pylori urease. Nat. Struct. Biol. 2001, 8, 505-509. [CrossRef]

32. Balasubramanian, A.; Ponnuraj, K. Crystal Structure of the First Plant Urease From Jack Bean: 83 Years of Journey From Its First Crystal to Molecular Structure. J. Mol. Biol. 2010, 400, 274-283. [CrossRef] [PubMed]

33. Whitmire, J.M.; Merrell, D.S. Successful Culture Techniques for Helicobacter Species: General Culture Techniques for Helicobacter pylori. In Helicobacter Species; Humana Press: Totowa, NJ, USA, 2012; pp. 37-40.

34. Fan, T.Y.; Hu, X.X.; Wang, Y.X.; You, X.F.; Song, D.Q. Anti-MRSA activities of cycloberberine derivatives with a novel chemical scaffold. Acta Pharm. Sin. 2019, 54, 1627-1635.

35. Wu, D.W.; Yu, X.D.; Xie, J.H.; Su, Z.Q.; Su, J.Y.; Tan, L.R.; Huang, X.Q.; Chen, J.N.; Su, Z.R. Inactivation of jack bean urease by scutellarin: Elucidation of inhibitory efficacy, kinetics and mechanism. Fitoterapia 2013, 91, 60-67. [CrossRef] [PubMed]

Sample Availability: Samples of the compounds 1a-i, 2, $\mathbf{3}$ and $\mathbf{4 a - i}$ are available from the authors.

(C) 2020 by the authors. Licensee MDPI, Basel, Switzerland. This article is an open access article distributed under the terms and conditions of the Creative Commons Attribution (CC BY) license (http://creativecommons.org/licenses/by/4.0/). 